\title{
Microalbuminuria and spot protein creatinine ratio in early pregnancy as a predictor of preeclampsia
}

\author{
Rupakala B. M., Gajjala Sai Sudha*, Sai Lakshmi M. P. A.
}

Department of Obstetrics and Gynecology, Rajarajeswari Medical College and Hospital, Bangalore, Karnataka, India

Received: 28 December 2020

Revised: 13 February 2021

Accepted: 15 February 2021

\author{
*Correspondence: \\ Dr. Gajjala Sai Sudha, \\ E-mail: dr.sudhareddy94@gmail.com
}

Copyright: ( $)$ the author(s), publisher and licensee Medip Academy. This is an open-access article distributed under the terms of the Creative Commons Attribution Non-Commercial License, which permits unrestricted non-commercial use, distribution, and reproduction in any medium, provided the original work is properly cited.

\begin{abstract}
Background: Hypertensive disorders complicate 5-10\% of all the pregnancies and preeclampsia is identified in $3.9 \%$. Preeclampsia is a pregnancy specific syndrome characterized by the development of hypertension and proteinuria in the second trimester of the pregnancy. Microalbuminuria and elevated spot protein creatinine ratio are commonly found in preeclampsia. The aim of this study was to determine microalbuminuria and spot creatinine ratio in early pregnancy as predictors of pre-eclampsia.

Methods: The study was conducted among 102 pregnant women by detecting the levels of albuminuria and spot protein creatinine ratio at 10-14 weeks period of gestation. Random urine sample of about $5 \mathrm{ml}$ was taken to analyse the samples for microalbuminuria and spot protein creatinine ratio. All the women included in the study were followed up till delivery to rule out the possibility of developing preeclampsia depending on their microalbumin and spot protein creatinine ratio values.

Results: Pregnant women who developed preeclampsia or eclampsia had significantly higher levels of microalbumin and spot protein creatinine ratio.

Conclusions: A detailed study among a larger group of population is required to determine that microalbuminuria and spot protein creatinine ratio in early pregnancy are definitive predictors of preeclampsia.
\end{abstract}

Keywords: Microalbuminuria, Spot protein creatinine ratio, Preeclampsia, Pregnancy

\section{INTRODUCTION}

Preeclampsia is a pregnancy specific syndrome defined as the new onset of hypertension and proteinuria during the second trimester or a new onset of hypertension and significant end-organ dysfunction with or without proteinuria after 20 weeks of gestation in a previously normotensive woman. ${ }^{1}$ The incidence of preeclampsia in nulliparous women ranged from $3-10 \%$ and for multiparas it is lesser than that. ${ }^{1}$ It is a potentially dangerous pregnancy complication with about 1 million cases being registered in India per year. In Indian scenario, the incidence of preeclampsia is $5.47 \%$ in primigravidae and $2.8 \%$ in multigravidae.
However, there is no gold standard method for diagnosing preeclampsia apart from it being characterized by the triad of hypertension, proteinuria and edema in the second trimester. The presence of proteinuria in preeclampsia patients suggests that detection of microalbuminuria and elevated protein creatinine ratio in 1 st trimester could be a predictor for development of preeclampsia in various studies conducted. ${ }^{2-6}$

Microalbuminuria is defined as a moderate increase in the level of urinary albumin excretion above normal levels in the absence of clinically detectable nephropathy. ${ }^{7-10}$ Persistent microalbuminuria indicates endothelial dysfunction and a high probability of damage to the glomerular filtration capacity of the kidney, which 
is a great diagnostic relevance in pregnancy as a possible predictor for developing preeclampsia. $^{2}$ Microalbuminuria is noted to be present if urinary microalbumin levels are within the range of $30-300 \mathrm{mg} /$. $^{7}$

Abnormal protein excretion is defined as spot protein creatinine ratio $\geq 0.3$ or persistent $30 \mathrm{mg} / \mathrm{dl}$ protein in a random urine sample. ${ }^{1}$ Spot protein creatinine ratio is used as an easy alternative to 24 hours urinary protein as the later is time consuming, collection is cumbersome, inconvenient to the patients and subject to errors such as incomplete collection leading to inaccuracies in 13-68\% of the collections. ${ }^{11-13}$ There are studies that show strong association between random protein-creatinine ratio and 24 hour urinary protein excretion, the international society for the study of hypertension in pregnancy has accepted this test as a method for identifying significant proteinuria. ${ }^{14}$ This suggests that microalbuminuria and elevated spot protein creatinine ratio in early pregnancy could predict preeclampsia.

\section{Objectives}

Objective of the current investigation was to investigate the role of microalbuminuria and elevated spot protein creatinine ratio in early pregnancy and its relation with development of preeclampsia.

\section{METHODS}

Current study was a prospective study conducted at Rajarajeswari medical college and hospital, Bengaluru, over a period of 9 months (February 2019 to October 2019). Random urine samples were taken from 102 pregnant women who attended antenatal checkups in their first trimester in order to detect the levels of albumin and spot protein creatinine ratio at 10-14 weeks period of gestation to analyse the development of preeclampsia till delivery.

\section{Inclusion criteria}

Inclusion criterion for current study was; pregnant women at 10-14 weeks period of gestation who were attending the OPD and were willing to give an informed written consent for the study.

\section{Exclusion criteria}

Exclusion criteria for current study were; pregnant women who were known cases of hypertension, diabetes mellitus and renal disorders were excluded from the study. Pregnant women with symptoms of UTI, multiple gestations, history of preeclampsia/eclampsia in previous pregnancies and history of renal surgeries in the past.

\section{Procedure}

A detailed obstetric and menstrual history was taken by following a pre-designed data sheet. General, systemic and obstetric examination carried out on the same day. These patients were under regular follow-up till the date of delivery. Specific note was made regarding the development of preeclampsia during gestational period and/or at the time of delivery. $10 \mathrm{ml}$ of venous blood was collected from each subject for a routine antenatal blood check-up to rule out diabetes, renal diseases and hyperlipidemia. All the selected subjects during their 1014 weeks period of gestation, gave their clean catch of urine sample $(5 \mathrm{ml})$ in a container after which the necessary biochemical tests were performed.

\section{Urine analysis}

Estimation of microalbuminuria was done by microalbumin-turbilatex method, a quantative turbimetric test for the measurement of microalbumin in human urine was done. The samples collected were adjusted to $7.0 \mathrm{pH}$ with $\mathrm{NaOH} / \mathrm{HCl}(1 \mathrm{~mol} / \mathrm{l})$. Sodium azide $(1 \mathrm{~g} / \mathrm{l})$ was added to prevent contamination. The urine was then centrifuged before testing. The sensitivity of the assay and target value of the calibrator were standardized against the international reference material CRM 470/RPPHS. Microalbuminuria concentration was calculated using the equation;

$$
\mathrm{C}=(\mathrm{A} 2-\mathrm{A} 1) \text { sample } /(\mathrm{A} 2-\mathrm{A} 1) \text { calibrator }
$$

Where $\mathrm{C}=$ concentration of sample $(\mathrm{mg} / \mathrm{l})$ to be determined. Estimation of total urine protein was done through calorimetric test. Urine was collected by standard procedures and volume was measured and stored at 2$8^{\circ} \mathrm{C}$. Total urine protein was estimated using the equation;

$$
\mathrm{C}=\mathrm{A} \times 1000 \times \mathrm{V}
$$

Where $\mathrm{C}=$ concentration of protein in 24 hours, $\mathrm{A}=$ sample concentration, 1000 was a factor for standard concentration and $\mathrm{V}=$ volume of urine ( $1 / 24$ hours). Estimation of urine creatinine was done using following procedure; random urine sample was collected and the exact volume was measured. It was diluted in 1:19 ratio with distilled water and the results were multiplied with dilution factor 20. Once the results were obtained, the subjects were followed up to delivery and the possibility of developing preeclampsia was observed with respect to their albumin and spot protein creatinine ratio values. The subjects were diagnosed with preeclampsia when they developed hypertension and proteinuria from second trimester onwards. The cut off value for microalbuminuria was taken as $30-300 \mathrm{mg} / \mathrm{l}$ and $\geq 0.3$ for elevated spot creatinine ratio. The collected data were expressed as mean $\pm \mathrm{SD}$.

\section{Statistical analysis}

The collected data were analysed with IBM.SPSS statistics software 23.0 version. Data was described using descriptive statistics, frequency analysis and percentage 
analysis for categorical variables and mean and SD were used reported for continuous variables. To find the significant difference between the bivariate samples in independent groups the unpaired sample t-test was used. To find the significance in categorical data Chi-Square test was used. In both the above statistical tools the probability value $<0.05$ was considered as significant level.

\section{RESULTS}

A total of 102 samples were collected during the study, out of which 29 subjects remained normotensive till delivery. Remaining 73 subjects developed preeclampsia (Table 3). Their mean systolic BP was $149.3 \pm 13.6 \mathrm{mmHg}$ and diastolic BP was $93.8 \pm 7.4 \mathrm{mmHg}$, microalbumin level was $50.2 \pm 25.4 \mathrm{mg} / \mathrm{l}$ and spot protein creatinine ratio was $0.5 \pm 0.5$ respectively (Table 1$)$.

Table 1: Parity of the study population.

\begin{tabular}{|lll|}
\hline & Frequency & Percentage (\%) \\
\hline Multi & 55 & 53.9 \\
\hline PRIMI & 47 & 46.1 \\
\hline Total & 102 & 100.0 \\
\hline
\end{tabular}

Table 2: The statistical significance of parity in association with development of preeclampsia.

\begin{tabular}{|c|c|c|c|c|c|c|c|}
\hline \multicolumn{8}{|c|}{ Parity with groups } \\
\hline & & & \multicolumn{2}{|l|}{ Groups } & \multirow{2}{*}{ Total } & \multirow{2}{*}{$\begin{array}{l}\chi 2- \\
\text { value }\end{array}$} & \multirow{2}{*}{ P-value } \\
\hline & & & E/PE & Normal & & & \\
\hline \multirow{4}{*}{ Parity } & \multirow{2}{*}{ MULTI } & Count & 17 & 38 & 55 & \multirow{6}{*}{0.36} & \multirow{6}{*}{$0.548 \#$} \\
\hline & & $\%$ & $58.6 \%$ & $52.1 \%$ & $53.9 \%$ & & \\
\hline & \multirow{2}{*}{ PRIMI } & Count & 12 & 35 & 47 & & \\
\hline & & $\%$ & $41.4 \%$ & $47.9 \%$ & $46.1 \%$ & & \\
\hline \multirow{2}{*}{ Total } & & Count & 29 & 73 & 102 & & \\
\hline & & $\%$ & $100.0 \%$ & $100.0 \%$ & $100.0 \%$ & & \\
\hline
\end{tabular}

\# No Statistical Significance at $\mathrm{P}>0.05$ level; This study shows no statistical significance between parity and its association with development of preeclampsia.

Table 3: The number of subjects who developed and did not develop preeclampsia/eclampsia.

\begin{tabular}{|lll|}
\hline \multicolumn{1}{|c|}{} & Frequency & Percent \\
\hline E/PE & 29 & 28.4 \\
\hline Normal & 73 & 71.6 \\
\hline Total & 102 & 100.0 \\
\hline
\end{tabular}

Out of 40 cases with microalbuminuria in early pregnancy, 28 cases had developed preeclampsia which is and out of 20 cases with elevated spot protein creatinine ratio, all the 20 had developed preeclampsia. Only 1 case with completely normal values during early pregnancy had developed preeclampsia. Pregnant women who developed preeclampsia were having significantly higher microalbumin levels and spot protein creatinine ratios when compared to normotensive pregnant women.

No statistical significance was observed when parity, age and their association with development of preeclampsia were studied in this study (Table 1-2). The statistical significance of age, microalbuminuria, spot protein creatinine ratio and mean blood pressure values is summarised in (Table 4).

Table 4: The statistical significance of age, early pregnancy microalbuminuria, early pregnancy spot protein creatinine ratio and mean blood pressure values in association with development of preeclampsia/eclampsia. The calculated mean values with SD and 'p' values of each factor are listed below.

\begin{tabular}{|c|c|c|c|c|c|c|}
\hline \multicolumn{7}{|c|}{ Groups comparison with unpaired t-test } \\
\hline Groups & & $\mathbf{N}$ & Mean & S.D & t-value & P-value \\
\hline \multirow{2}{*}{ Age } & $\mathrm{E} / \mathrm{PE}$ & 29 & 23.1 & 3.6 & \multirow{2}{*}{0.329} & \multirow{2}{*}{$0.743 \#$} \\
\hline & Normal & 73 & 22.8 & 3.6 & & \\
\hline \multirow{2}{*}{ UM } & $\mathrm{E} / \mathrm{PE}$ & 29 & 50.2 & 25.4 & \multirow{2}{*}{5.344} & \multirow{2}{*}{$0.0005 * *$} \\
\hline & Normal & 73 & 22.6 & 17.7 & & \\
\hline \multirow{2}{*}{ SBP1 } & $\mathrm{E} / \mathrm{PE}$ & 29 & 149.3 & 13.6 & \multirow{2}{*}{13.334} & \multirow{2}{*}{$0.0005 * *$} \\
\hline & Normal & 73 & 113.5 & 7.8 & & \\
\hline DBP1 & $\mathrm{E} / \mathrm{PE}$ & 29 & 90.8 & 7.4 & 13.241 & $0.0005 * *$ \\
\hline
\end{tabular}

Continued. 


\begin{tabular}{|c|c|c|c|c|c|c|}
\hline \multicolumn{7}{|c|}{ Groups comparison with unpaired t-test } \\
\hline & Normal & 73 & 71.5 & 6.3 & & \\
\hline \multirow{2}{*}{ SBP2 } & $\mathrm{E} / \mathrm{PE}$ & 29 & 146.8 & 11.3 & \multirow{2}{*}{17.099} & \multirow{2}{*}{$0.0005 * *$} \\
\hline & Normal & 73 & 111.7 & 8.4 & & \\
\hline \multirow{2}{*}{ DBP2 } & $\mathrm{E} / \mathrm{PE}$ & 29 & 93.5 & 7.2 & \multirow{2}{*}{13.340} & \multirow{2}{*}{$0.0005 * *$} \\
\hline & Normal & 73 & 68.2 & 9.1 & & \\
\hline \multirow{2}{*}{ Acratio } & $\mathrm{E} / \mathrm{PE}$ & 29 & 0.5 & 0.5 & \multirow{2}{*}{5.418} & \multirow{2}{*}{$0.0005 * *$} \\
\hline & Normal & 73 & 0.2 & 0.2 & & \\
\hline
\end{tabular}

\# No Sig at $\mathrm{P}>0.05$ level and ** Highly Sig $\mathrm{P}<0.01$ level; This study shows high statistical significance between microalbuminuria, spot protein creatinine ratio and development of preeclampsia. No statistical significance was observed with age.

\section{DISCUSSION}

In current study, microalbumin and spot protein creatinine ratio of 102 pregnant women was investigated and observed to be significantly higher, all women developed preeclampsia in later stage of pregnancy. Various studies have been conducted so far to see the association of spot protein creatinine ratio, microalbuminuria and development of preeclampsia. Kaur et al had reported that microalbuminuria and elevated albumin-creatinine ratio were having higher statistical significance in predicting preeclampsia. ${ }^{15}$ Similarly, Fatema et al had also reported in their study that patients with microalbuminuria developed preeclampsia eventually. ${ }^{16}$ In another study Fady et al had reported that, albumin creatinine ratio is significantly higher in patients with severe preeclampsia than in those with mild form of the disease. ${ }^{17}$ The presence of microalbuminuria in some otherwise symptom free patient confirms that changes in renal function are present in patients in whom preeclampsia will eventually develop, suggesting that early pregnancy levels of microalbuminuria can be used as predictors of preeclampsia with high negative predictive value. ${ }^{18}$ Salako et al and other reports found that microalbuminuria might be a good predictor of preeclampsia with high sensitivity but a low positive predictive value. ${ }^{19-23}$ It is clearly understood that there is need for more detailed studies in order to establish the usefulness of microalbuminuria and spot protein creatinine ratio in predicting preeclampsia.

\section{Limitations}

Limitations of current study were; although 24 hours of urine collection is the gold standard for quantifying urinary albumin, spot creatinine ratio has been used in the study because it is more likely to reflect clinical practice for a screening test. 24 hours of urine collection is a timeconsuming procedure unlike spot protein creatinine ratio.

\section{CONCLUSION}

This study was conducted on a smaller population of pregnant women, so a detailed study to assess the association of preeclampsia with early pregnancy microalbuminuria and elevated spot protein creatinine ratio along with the other established markers is needed.

\section{ACKNOWLEDGMENTS}

Authors would like to thank Mr. Venkatesan for the aid in statistical analysis.

\section{Funding: No funding sources \\ Conflict of interest: None declared}

Ethical approval: The study was approved by the Institutional Ethics Committee

\section{REFERENCES}

1. Gestational hypertension and preeclampsia: ACOG practice bulletin, number 222. Obstet Gynecol. 2020; 135(6):e237-60.

2. Kaur IP, Shukla A, Gangopadhyay S, Gupta A, Sarkar G. Levels of microalbuminuria in prediction of pre-eclampsia: A hospital based study. Int J Clin Biochem Res. 2016;3(4):354-6.

3. Mishra VV, Goyal PA, Priyankur R, Choudhary S, Aggarwal RS, Gandhi K, Vyas B, Hokabaj S. Evaluation of spot urinary albumin-creatinine ratio as screening tool in prediction of pre-eclampsia in early pregnancy. J Obstet Gynaecol. 2017;67(6):405-8.

4. Baweja S, Kent A, Masterson R, Roberts S, McMahon L. Prediction of pre-eclampsia in early pregnancy by estimating the spot urinary albumin: creatinine ratio using high-performance liquid chromatography. BJOG. 2011;118:1126-32.

5. Somanathan N, Farrell T, Galimberti A. A comparison between 24-h and 2-h urine collection for the determination of proteinuria. J Obstet Gynaecol. 2003;23:378-80.

6. Gupta N, Gupta T, Asthana D. Prediction of preeclampsia in early pregnancy by estimating the spot urinary albumin/creatinine ratio. J Obstet Gynaecol. 2017;67(4):258-62.

7. Rodriguez MH, Masaki DI, Mestman J, Kumar D, Rude R. Calcium/creatinine ratio and microalbuminuria in the prediction of preeclampsia. Am J Obstet Gynecol. 1988;159(6):1452-5.

8. Mogensen CE. Microalbuminuria, blood pressure and diabetic renal disease: origin and development of ideas. Diabetologia. 1999;42(3):263-85. 
9. Mogensen CE, Christensen CK, Vittinghus E. The stages in diabetic renal disease. With emphasis on the stage of incipient diabetic nephropathy. Diabetes. 1983;32(2):64-78.

10. Bending JJ, Viberti GC, Watkins PJ, Keen H. Intermittent clinical proteinuria and renal function in diabetes: evolution and the effect of glycaemic control. Br Med J. 1986;292(6513):83-6.

11. Bezerra HMS, Marques LL, Murthi P, da Silva CF. Prevention of preeclampsia. J Pregnancy. 2012; 2012:435090.

12. Bell MJ. A historical overview of preeclampsiaeclampsia. J Obstet Gynecol Neonatal Nurs. 2010;39 (5):510-8.

13. Prakash J, Pandey LK, Singh AK, Kar B. Hypertension in pregnancy: hospital based study. J Assoc Physicians India. 2006;54:273-8.

14. Modak R, Das A, Pal A, Ray DK, Pal A. Evaluation of spot urinary protein-creatinine ratio as a predictor of preeclampsia. Int J Clin Obstet Gynaecol. 2019; 3(6):290-3.

15. Kaur IP, Shukla A, Gangopadhyay S, Gupta A, Sarkar G. Levels of microalbuminuria in prediction of pre-eclampsia: A hospital based study. Int J Clin Biochem Res. 2016;3(4):355.

16. Kaniz F, Khatun M, Safika A, Liaquat A. Role of urinary albumin in the prediction of preeclampsia. Faridpur Med Col J. 2011;6:14-8.

17. Fady SM, Mohamed SB, Rana A, Kaffash D. Albumin to creatinine ratio in a random urine sample: Correlation with severity of preeclampsia. Alexandria J Med. 2014;50(2):139-42.

18. Brown MA, Lindheimer MD, de Swiet M, Van Assche A, Moutquin JM. The classification and diagnosis of the hypertensive disorders of pregnancy: statement from the International society for the study of hypertension in pregnancy (ISSHP). Hypertens Pregnancy. 2001;20(1):9-15.

19. Salako BL, Olayemi O, Odukogbe AT, Adedapo KS, Aimakhu CO, Alu FE, et al. Microalbuminuria in pregnancy as a predictor of preeclampsia and eclampsia. West Afr J Med. 2003;22(4):295-300.

20. Bar J, Hod M, Erman A, Friedman S, Gelerenter I, Kaplan B, et al. Microalbuminuria as an early predictor of hypertensive complications in pregnant women at high risk. Am J Kidney Dis. 1996; 28(2):220-5.

21. Chhabra S, Gandhi D. Prediction of pregnancyinduced hypertension/ pre-eclampsia by detecting microalbuminuria. J Obstet Gynecol. 2002;52(1):5660 .

22. Geographic variation in the incidence of hypertension in pregnancy, world health organization international collaborative study of hypertensive disorders of pregnancy. Am J Obstet Gynecol. 1988; 158(1):80-3.

23. Poon LC, Kametas N, Bonino S, Vercellotti E, Nicolaides KH. Urine albumin concentration and albumin-to-creatinine ratio at $11(+0)$ to $13(+6)$ weeks in the prediction of pre-eclampsia. BJOG. 2008;115(7):866-73.

Cite this article as: Rupakala BM, Sudha GS, Lakshmi SMPA. Microalbuminuria and spot protein creatinine ratio in early pregnancy as a predictor of preeclampsia. Int J Reprod Contracept Obstet Gynecol 2021;10:1452-6. 